\title{
Dielectric measurements on PWB materials at microwave frequencies
}

\author{
A TANWAR*, K K GUPTA, P J SINGH and Y K VIJAY \\ Department of Physics, M.S.J. College, Bharatpur 321 001, India \\ 'Department of Physics, University of Rajasthan, Jaipur 302 004, India
}

MS received 3 September 2005; revised 22 November 2005

\begin{abstract}
In quest of finding new substrate for printed wiring board (PWB) having low dielectric constant, we have made PSF/PMMA blends and evaluated the dielectric parameters at $8.92 \mathrm{GHz}$ frequency and at $35^{\circ} \mathrm{C}$ temperature. Incorporating PMMA in PSF matrix results in reduced dielectric constant than that of pure PSF. The dielectric parameters of pure PMMA and PSF films of different thicknesses have also been obtained at microwave frequencies. We have used dielectric data at microwave frequencies as a tool to evaluate optical constants, absorption index ' $K$ ' and refractive index ' $n$ '. The blends of PSF/PMMA may be used as base materials for PWBs.
\end{abstract}

Keywords. Dielectric constant; PWB; dielectric loss; absorption index.

\section{Introduction}

Dielectric materials have many important functions in the microelectronics industry. New packaging technology requires substrates with low permittivity. As electrical components are miniaturized, the need for well characterized dielectric measurements on thin materials is in great demand (Bahl and Ely 1990; Chang 1993; Baker-Jarvis and Janezic 1994; Baker-Jarvis et al 1994; Chang and Agrawal 1994; Paulter 1998). Accurate measurement of complex permittivity is needed for circuit design, minimization of cross talks, and characterization of signal-propagation speed.

Substrates are used in PWBs, central processing units and for thin films. Important properties of PWB and other substrate materials include low electrical loss, high thermal conductance, low thermal expansion, and high interfacial adhesion to metal surfaces or other films. Low electrical loss decreases heating and signal attenuation, high thermal conductivity rapidly removes heat from the circuit, and low thermal expansion promotes circuit durability. In high speed or high frequency circuits the speed of signal propagation is important. The signal-propagation delay depends on both the dielectric constant and transmissionline structure. Dielectrics with low loss provide reduced attenuation and heating in circuits. They also provide greater signal integrity.

Polymers are good choice for being used as substrates in PWBs (Araktingi and Hoard 1999; Baker-Jarvis et al 2001). Polysulphone is one such potential polymer for PWBs (Baker-Jarvis et al 2001). It is thought that if a

\footnotetext{
*Author for correspondence (tanwar17msj@yahoo.com)
}

blend of PSF and PMMA is prepared, then it may serve as a better choice for the substrate in microelectronics circuits. Further it will also reduce cost of the material because PMMA is cheaper than PSF.

In the present study, blends of PSF and PMMA have been prepared and investigations in the form of thin films have been taken up at microwave frequencies. The experimental data have been used to evaluate various dielectric parameters.

\section{Experimental}

\subsection{Sample preparation}

Polysulphone (PSF) supplied by Gharda Chemicals Ltd., Bharuch, Gujarat (India) and poly (methyl methacrylate) or (PMMA) supplied by HiMedia Laboratories Pvt. Ltd., Mumbai (India), were used for the study.

Thin films of PMMA and PSF of variable thickness were prepared by solution cast method. For preparing blends of polysulphone and PMMA in variable proportions, the granules of PMMA and PSF were dissolved in common solvent i.e. dichloromethane, and stirred thoroughly for a few hours to ensure mixing. The mixed solution was used to prepare blend membrane by solution cast method. Blends of PSF/PMMA in the ratio 50:50, 60:40, 70:30, $80: 20,90: 10$ were prepared.

\subsection{Dielectric measurements}

For microwave measurements of dielectric parameters of thin films, we have used the technique developed by Dube 
(1984) and Dube and Natarajan (1973). The sample was mounted along the axis of the waveguide (figure 1). With this configuration, the electric field acts in the plane of the film. The advantage of this method is that the thin specimen is placed longitudinally at the centre of the broad side of a hollow rectangular waveguide excited in the $\mathrm{TE}_{10}$ mode so that the whole specimen remains in maximum electric field. Standing waves are produced in the rectangular waveguide by short-circuiting the system. These are detected in the slotted line by means of a traveling waveguide detector.

Initially, the movable probe is placed at a minimum of the standing wave. The sample, length $L \mathrm{~cm}$, is then placed in the sample holder, which is a waveguide $(\sim 10 \mathrm{~cm}$ long) with a fine, accurately cut, longitudinal slot at the middle. This causes the minimum to shift. Assuming this shift to be $x \mathrm{~cm}$ the phase introduced by the specimen per unit length is

$$
\beta_{\mathrm{s}}=\beta_{0} x / L
$$

where $\beta_{0}$ is $2 \pi / \lambda_{\mathrm{g}}, \lambda_{\mathrm{g}}$ being the guide wavelength in air. Thus, the total phase constant, $\beta_{\mathrm{r}}$, is given by

$$
\beta_{\mathrm{r}}=\beta_{0}(1+x / L)
$$

For the measurement of dielectric loss, the standing wave ratio (VSWR) is taken with and without the specimen. Let these be $\rho_{1}$ and $\rho_{2}$, then

$$
\begin{aligned}
& \rho_{1}=\frac{1+r}{1-r}=\exp (-\alpha), \\
& \rho_{2}=\frac{1+r^{\prime}}{1-r^{\prime}}=\exp \left[-\left(\alpha+2 \beta_{\mathrm{i}} L\right)\right],
\end{aligned}
$$

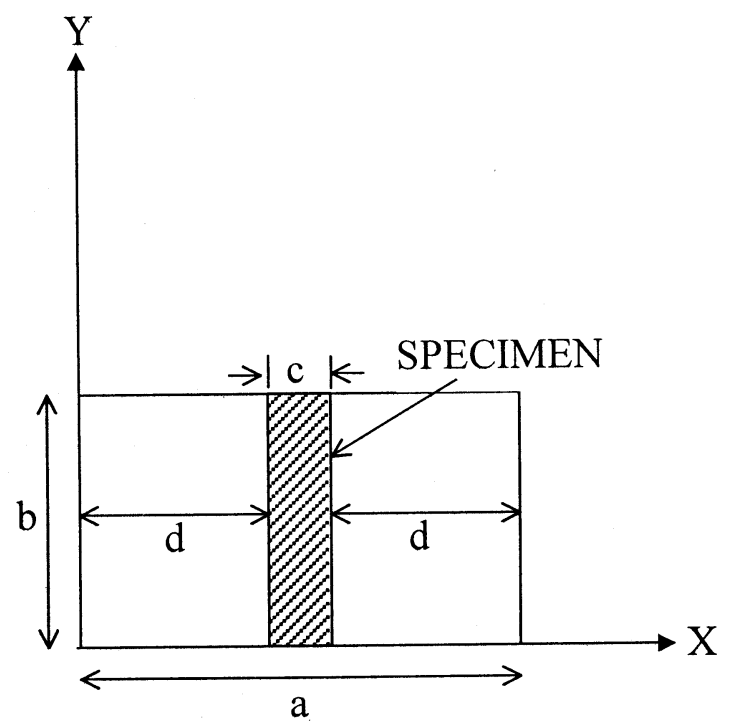

Figure 1. Cross-section of a rectangular waveguide with specimen. where $r$ and $r^{\prime}$ are the reflection coefficients of the system without and with the sample and $\alpha$ the attenuation constant. Hence $\beta_{\mathrm{i}}$ can be calculated from (1) and (2).

The complex permittivity, $\varepsilon\left(=\varepsilon_{\mathrm{r}},-i \varepsilon_{\mathrm{i}}\right)$, is determined from the phase shift and attenuation measurements using the following equations

$$
\begin{aligned}
& \varepsilon_{\mathrm{r}}=\frac{1}{k^{2}}\left[\beta_{\mathrm{r}}^{2}-\beta_{\mathrm{i}}^{2}+\left(\frac{a_{1} a_{3}+a_{2} a_{4}}{a_{3}^{2}+a_{4}^{2}}\right) \frac{2}{c d}\right], \\
& \varepsilon_{\mathrm{i}}=\frac{1}{k^{2}}\left[2 \beta_{\mathrm{i}} \beta_{\mathrm{r}}-\left(\frac{a_{2} a_{3}-a_{1} a_{4}}{a_{3}^{2}+a_{4}^{2}}\right) \frac{2}{c d}\right],
\end{aligned}
$$

where

$$
\begin{aligned}
& a_{1}=d \operatorname{Re}\left(k^{2}-\beta_{\mathrm{r}}^{2}\right)^{1 / 2}, \\
& a_{2}=d \operatorname{Im}\left(k^{2}-\beta_{\mathrm{r}}^{2}\right)^{1 / 2}, \\
& a_{3}=\frac{2 \sin 2 a_{1}}{\exp \left(2 a_{2}\right)+\exp \left(-2 a_{2}\right)+2 \cos 2 a_{1}}, \\
& a_{4}=\frac{\exp \left(2 a_{2}\right)-\exp \left(-2 a_{2}\right)}{\exp \left(2 a_{2}\right)+\exp \left(-2 a_{2}\right)+2 \cos 2 a_{1}},
\end{aligned}
$$

$k=\omega / c_{0}$ is the free-space propagation vector, where $\omega$ is the angular frequency and $c_{0}$ the velocity of light, $c$ the thickness of the film and $d=\frac{1}{2}(a-c), a$ being the width of the waveguide (figure 1). The values of $\beta_{\mathrm{r}}$ and $\beta_{\mathrm{i}}$ are used in (3) and (4) to calculate $\varepsilon_{\mathrm{r}}$ and $\varepsilon_{\mathrm{i}}$. Being electrodeless technique, measurements at microwave frequencies are free from electrode polarization and associated problems and thus yield real material parameters.

\section{Results and discussion}

In table 1 , dielectric constant $\left(\varepsilon_{\mathrm{r}}\right)$, dielectric loss $\left(\varepsilon_{\mathrm{i}}\right)$, loss tangent $(\tan \delta)$, a.c. conductivity $(\sigma)$, absorption index $(K)$ and refractive index $(n)$ have been reported for PMMA and PSF at $8.92 \mathrm{GHz}$ frequency and at $35^{\circ} \mathrm{C}$ temperature for films of varying thickness.

In table 2 , dielectric constant $\left(\varepsilon_{\mathrm{r}}\right)$, dielectric loss $\left(\varepsilon_{\mathrm{i}}\right)$, loss tangent $(\tan \delta)$, a.c. conductivity $(\sigma)$, absorption index $(K)$ and refractive index $(n)$ have been reported for PSF/PMMA blends of thickness $100 \mu \mathrm{m}$ of various doping percentages at $8.92 \mathrm{GHz}$ frequency and at $35^{\circ} \mathrm{C}$ temperature.

\subsection{Dielectric constant and loss}

Dielectric constant $\left(\varepsilon_{\mathrm{r}}\right)$ for PMMA at $8.92 \mathrm{GHz}$ and at $35^{\circ} \mathrm{C}$ temperature has been obtained in the range $2 \cdot 67-2.47$ 
Table 1. Dielectric parameters, absorption index and refractive index for pure PSF and pure PMMA at $8.92 \mathrm{GHz}$ frequency and at $35^{\circ} \mathrm{C}$ temperature.

\begin{tabular}{|c|c|c|c|c|c|c|c|}
\hline $\begin{array}{l}\text { Thickness, } \\
C(\mu \mathrm{m})\end{array}$ & $\begin{array}{c}\text { Dielectric } \\
\text { constant } \\
\left(\varepsilon_{\mathrm{r}}\right)\end{array}$ & $\begin{array}{c}\text { Dielectric } \\
\text { loss } \\
\left(\varepsilon_{\mathrm{i}}\right)\end{array}$ & $\begin{array}{c}\text { Loss } \\
\text { tangent } \\
(\tan \delta)\end{array}$ & $\begin{array}{l}\text { Relaxation } \\
\text { time } \\
\left(\tau \times 10^{13} \mathrm{~s}\right)\end{array}$ & $\begin{array}{l}\text { Conductivity } \\
(\mathrm{mho} / \mathrm{m}) \\
(\sigma)\end{array}$ & $\begin{array}{l}\text { Absorption } \\
\text { index } \\
(K)\end{array}$ & $\begin{array}{l}\text { Refractive } \\
\text { index } \\
(n)\end{array}$ \\
\hline \multicolumn{8}{|l|}{ PSF } \\
\hline 50 & $2 \cdot 99$ & $0 \cdot 188$ & $6.30 \times 10^{-2}$ & $11 \cdot 2$ & $9.3 \times 10^{-2}$ & $3.14 \times 10^{-2}$ & 1.73 \\
\hline 100 & 2.99 & $0 \cdot 213$ & $7 \cdot 11 \times 10^{-2}$ & $12 \cdot 7$ & $10.5 \times 10^{-2}$ & $3.55 \times 10^{-2}$ & 1.73 \\
\hline 150 & $2 \cdot 94$ & $0 \cdot 244$ & $8.32 \times 10^{-2}$ & 14.8 & $12 \cdot 1 \times 10^{-2}$ & $4.15 \times 10^{-2}$ & 1.72 \\
\hline 200 & $2 \cdot 97$ & $0 \cdot 261$ & $8.79 \times 10^{-2}$ & $15 \cdot 7$ & $12.9 \times 10^{-2}$ & $4.38 \times 10^{-2}$ & 1.73 \\
\hline \multicolumn{8}{|l|}{ PMMA } \\
\hline 60 & $2 \cdot 67$ & 0.036 & $1.30 \times 10^{-2}$ & $2 \cdot 4$ & $1.8 \times 10^{-2}$ & $0.68 \times 10^{-2}$ & 1.63 \\
\hline 100 & $2 \cdot 52$ & 0.057 & $2.25 \times 10^{-2}$ & $4 \cdot 0$ & $2.8 \times 10^{-2}$ & $1.13 \times 10^{-2}$ & 1.58 \\
\hline 150 & 2.53 & 0.071 & $2.90 \times 10^{-2}$ & $5 \cdot 0$ & $3.6 \times 10^{-2}$ & $1.42 \times 10^{-2}$ & 1.59 \\
\hline 200 & $2 \cdot 47$ & 0.010 & $3.70 \times 10^{-2}$ & $6 \cdot 6$ & $4.5 \times 10^{-2}$ & $1.85 \times 10^{-2}$ & 1.57 \\
\hline
\end{tabular}

Table 2. Dielectric parameters, absorption index and refractive index for PSF/PMMA blends at $8.92 \mathrm{GHz}$ frequency and at $35^{\circ} \mathrm{C}$ temperature.

\begin{tabular}{|c|c|c|c|c|c|c|c|}
\hline $\begin{array}{l}\text { Composition } \\
\text { of PSF/PMMA } \\
\text { blend }\end{array}$ & $\begin{array}{l}\text { Dielectric } \\
\text { constant } \\
\left(\varepsilon_{\mathrm{r}}\right)\end{array}$ & $\begin{array}{c}\text { Dielectric } \\
\text { loss } \\
\left(\varepsilon_{\mathrm{i}}\right)\end{array}$ & $\begin{array}{c}\text { Loss } \\
\operatorname{tangent} \\
(\tan \delta)\end{array}$ & $\begin{array}{l}\text { Relaxation } \\
\text { time } \\
\left(\tau \times 10^{13} \mathrm{~s}\right)\end{array}$ & $\begin{array}{l}\text { Conductivity, } \sigma \\
(\mathrm{mho} / \mathrm{m})\end{array}$ & $\begin{array}{l}\text { Absorption } \\
\text { index } \\
(K)\end{array}$ & $\begin{array}{l}\text { Refractive } \\
\text { index } \\
(n)\end{array}$ \\
\hline \multicolumn{8}{|c|}{ PSF/PMMA blend (film thickness $=100 \mu \mathrm{m}$ ) } \\
\hline $100 \%+0 \%$ & 2.99 & 0.213 & $7 \cdot 11 \times 10^{-2}$ & $12 \cdot 7$ & $10.5 \times 10^{-2}$ & $3.55 \times 10^{-2}$ & 1.73 \\
\hline $90 \%+10 \%$ & 2.94 & 0.505 & $17 \cdot 17 \times 10^{-2}$ & $30 \cdot 7$ & $25 \cdot 0>$ & $8.52 \times 10^{-2}$ & 1.72 \\
\hline $80 \%+20 \%$ & $2 \cdot 82$ & 0.483 & $17 \cdot 13 \times 10^{-2}$ & $30 \cdot 6$ & $24.0 \times 10^{-2}$ & $8.50 \times 10^{-2}$ & 1.68 \\
\hline $70 \%+30 \%$ & $2 \cdot 70$ & 0.433 & $16.05 \times 10^{-2}$ & $28 \cdot 6$ & $21.5 \times 10^{-2}$ & $7.97 \times 10^{-2}$ & 1.65 \\
\hline $60 \%+40 \%$ & $2 \cdot 55$ & $0 \cdot 292$ & $11.43 \times 10^{-2}$ & $20 \cdot 4$ & $14.5 \times 10^{-2}$ & $5 \cdot 70 \times 10^{-2}$ & $1 \cdot 60$ \\
\hline $50 \%+50 \%$ & 2.71 & $0 \cdot 207$ & $7.65 \times 10^{-2}$ & $13 \cdot 7$ & $10 \cdot 3 \times 10^{-2}$ & $3 \cdot 82 \times 10^{-2}$ & 1.65 \\
\hline $0 \%+100 \%$ & $2 \cdot 52$ & 0.057 & $2 \cdot 25 \times 10^{-2}$ & $4 \cdot 0$ & $2.8 \times 10^{-3}$ & $1.13 \times 10^{-2}$ & 1.58 \\
\hline
\end{tabular}

and loss tangent $(\tan \delta)$ has been obtained in the range $1.30 \times 10^{-2}-3.70 \times 10^{-2}$ for film thickness, 60-200 $\mu \mathrm{m}$, respectively. These results are in agreement with the values of dielectric constant and loss tangent reported by Riddle and Baker-Jarvis (2003).

Dielectric constant $\left(\varepsilon_{\mathrm{r}}\right)$ for polysulphone at $8.92 \mathrm{GHz}$ and at $35^{\circ} \mathrm{C}$ temperature has been obtained in the range 2.99-2.94 and loss tangent $(\tan \delta)$ has been obtained in the range $6.30 \times 10^{-2}$ to $8.79 \times 10^{-2}$ for films of varying thickness. These results are in agreement with the values of dielectric constant and loss tangent reported by Riddle and Baker-Jarvis (2003).

As we see from table 2, for the PSF/PMMA blend of various compositions, reduced values of dielectric constant $\left(\varepsilon_{\mathrm{r}}\right)$ than pure polysulphone are obtained. For PSF/PMMA blends we get the values of $\varepsilon_{\mathrm{r}}$ in the range 2.55-2.94. To our knowledge, dielectric constant values of PSF/PMMA blends at microwave frequencies are not reported in literature.

The holes or voids within the polymer are collectively called free volume. One of the reasons for the reduced dielectric constant in the blends may be the enhanced free volume. The morphology of blends characterized them to be of immiscible category. It seems that more voids have been created at the phase boundaries, enhancing free volume. Enhanced free volume lowers polarization by decreasing the number of polarization groups per unit volume. A correlation of high free volume and low dielectric constant has been previously reported for polyimides (Bur 1985; Singh et al 1985). Formation of blend may have resulted in increased free volume.

Loss tangent for PSF/PMMA blends of $90: 10,80: 20$, $70: 30,60: 40$ and $50: 50$ has been obtained in the range $17 \cdot 17 \times 10^{-2}-7.65 \times 10^{-2}$. The origins of microwave dielectric loss in polymers are attributed to dipolar absorption dispersions in both crystalline and amorphous polymers, dipolar losses due to impurities and photon-phonon absorption spectra corresponding to the density of states in amorphous regions of polymer (Eftekhari et al 1992).

\subsection{Relaxation time and conductivity}

The relaxation time is calculated by using the relation, $\tau=\varepsilon_{\mathrm{i}} / \omega \varepsilon_{\mathrm{r}}$. Relaxation time for PMMA has been obtained in the order of $10^{-13} \mathrm{~s}$. The values are in agreement with the $\tau$ values obtained by Khare et al (1993) and in case of PSF films the order remains the same. Relaxation time for PSF/PMMA blends also come out to be of the order 

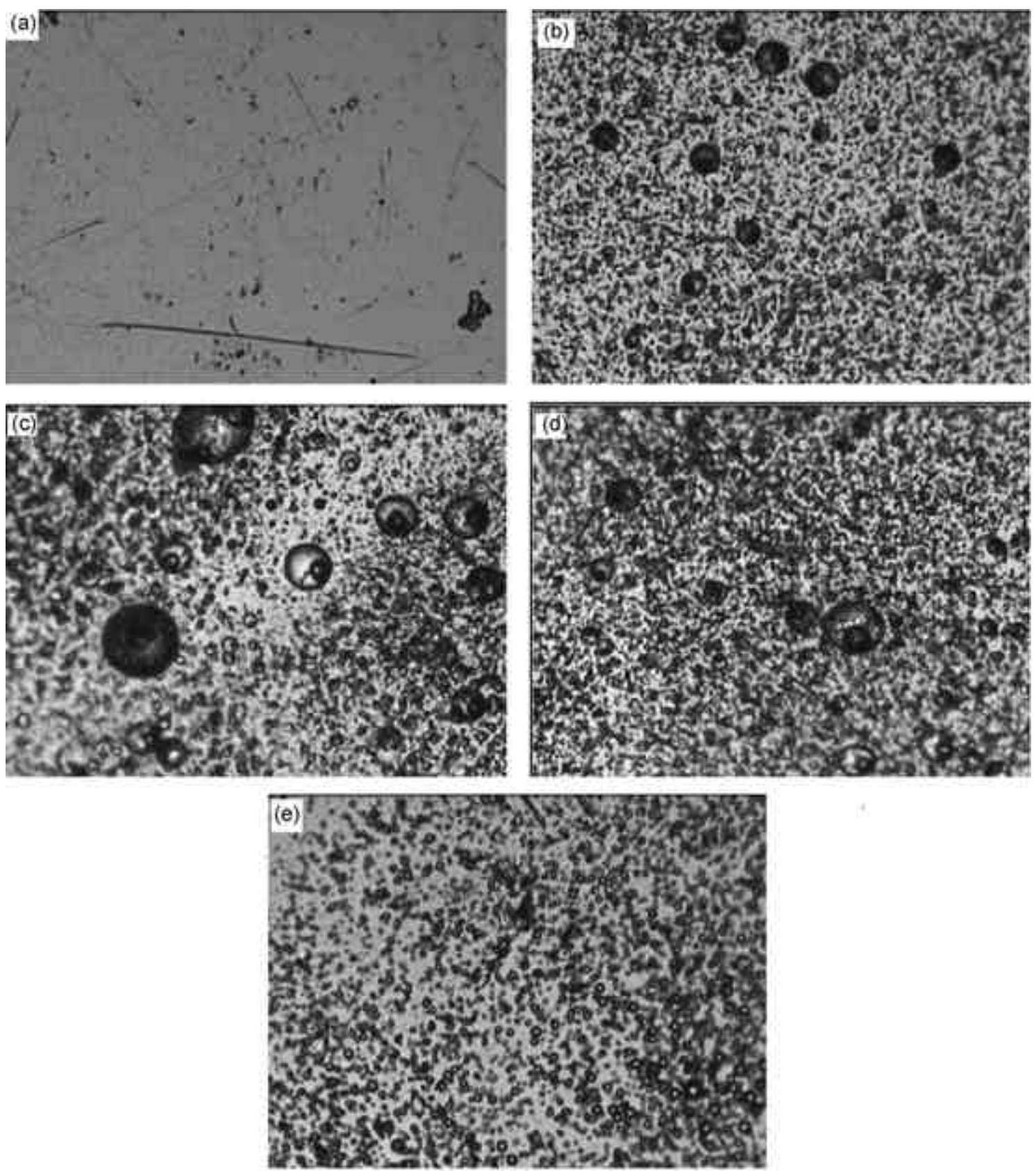

Figure 2. Micrographs of PSF/PMMA blends taken by optical microscope: (a) $100: 0$, (b) $80: 20$, (c) $70: 30$, (d) $60: 40$ and (e) $50: 50$.

of $10^{-13} \mathrm{~s}$. However, it comes out to be a bit higher in magnitude in the blends as compared to that of pure PSF. The increased $\tau$ values in blends may be due to the intermolecular interactions between PSF and PMMA molecules.

The a.c. conductivity is obtained by using the relation, $\sigma_{\text {a.c. }}=\omega \varepsilon_{0} \varepsilon_{\mathrm{i}}$. For PMMA films it comes out in the range $1.8 \times 10^{-2}-4.5 \times 10^{-2} \mathrm{mho} / \mathrm{m}$ whereas for polysulphone films a.c. conductivity is obtained in the range $9.3 \times 10^{-2}$ $12.9 \times 10^{-2} \mathrm{mho} / \mathrm{m}$. The increase in conductivity with thickness is accounted for the increase in the number of dipoles.
The conductivity of PSF/PMMA blends is obtained in the range $10.3 \times 10^{-2}-25 \cdot 0 \times 10^{-2}$ for different compositions of PMMA in blends.

It is observed that addition of PMMA to PSF increases the conductivity over that of PSF. This may perhaps be due to the modification of trap structure introduced by the addition of PMMA. The PMMA molecules in the blend might be producing additional traps of shallow as well as deeper depths, thus providing conducting pathways for the charge carriers. 


\subsection{Absorption index and refractive index}

Using the relations (Vankrevelen and Hoftyzer 1976)

$$
\tan \delta=\frac{2 K}{1-K^{2}} \text { and } \varepsilon_{\mathrm{i}}=2 n^{2} K
$$

The optical constants viz. absorption index $(K)$ and refracting index $(n)$, have been calculated by using the dielectric data. For pure PMMA and PSF, $K$ increases with thickness. For PMMA films it varies in the range $0.68 \times$ $10^{-2}-1.85 \times 10^{-2}$ for thickness $60 \mu \mathrm{m}, 100 \mu \mathrm{m}, 150 \mu \mathrm{m}$, $200 \mu \mathrm{m}$, respectively. For PSF films, it varies in the range $3.14 \times 10^{-2}-4.38 \times 10^{-2}$ for films of thickness $50 \mu \mathrm{m}$, $100 \mu \mathrm{m}, 150 \mu \mathrm{m}, 200 \mu \mathrm{m}$, respectively.

In the PSF/PMMA blends where the thickness for all compositions is $100 \mu \mathrm{m}$, enhancement in absorption index values is noted. For various blends under investigation, $K$ comes out to be in the range $3.82 \times 10^{-2}-8.52 \times 10^{-2}$.

The values of refractive index $(n)$ are found to be in the range 1.57-1.63 for PMMA and 1.72-1.73 for PSF. In case of PSF/PMMA blends the values of refractive index obtained are in the range $1.60-1.72$.

\subsection{Morphology of the blends}

Some of the micrographs taken by optical microscope of blends of PSF/PMMA are shown in figure 2. As seen in the micrographs of the blend, $80: 20$ i.e. PSF is $80 \%$ and PMMA is $20 \%$, we find that there is not a single phase, instead PMMA separates from PSF into little spherical blobs. In the blend PSF and PMMA are phase separated. As we go on increasing the amount of PMMA in the blend the number of spherical blobs goes on increasing (as seen from micrographs taken by optical microscope of blends, $70: 30,60: 40$ ). The spherical blobs of PMMA are separated from each other by a sea of polysulphone. When the two polymers are taken in equal amounts to form a 50:50 blend, PSF and PMMA form two cocontinuous phases. This means both phases will bear the load of any stress on the material, so it will be stronger. The conclusion is that when PMMA is blended with polysulphone we get immiscible blends as also seen from the morphology of these blends.

Similar results have been reported by Fayt et al (1985) for the polystyrene and polybutadiene blends. They observed that polystyrene and polybutadiene when mixed together also forms immiscible blends and in polystyrene/ polybutadiene blends, polybutadiene separates from polystyrene into little spherical blobs.

Callaghan and Paul (1994) reported that only for low molecular weights of PMMA we can make miscible blends with PSF but as the molecular weight of PMMA is increased, phase separation starts and we get immiscible blends. In our case mol. wt. of PMMA used is 15,000, which is quite large in comparison to mol. wt of PMMA used by Callaghan and Paul (1994). So the formation of spherical blobs resulting in immiscible blends of PSF/PMMA are justified in the present investigation.

\section{Conclusions}

As search for a better PWB substrate is going on, dielectric constant $\left(\varepsilon_{\mathrm{r}}\right)$ and dissipation factor i.e. loss tangent $(\tan \delta$ ), are the two main deciding factors of a PWB substrate. The values of $\varepsilon_{\mathrm{r}}$ and $\tan \delta$ in the present investigation for PSF/PMMA blends are in the same order as for the PWB materials suggested by Araktingi and Hoard (1999). Keeping this in mind, based on our studies we suggest PSF/PMMA blend as a good choice for PWB substrate. The results show that the blend, $60: 40$, has lowest value of dielectric constant and the blend, 50:50, has lowest value of dissipation factor as compared to other blend compositions. Depending on the requirements, any of $60: 40$ or $50: 50$ blends of PSF/PMMA can be used as PWB substrate.

\section{Acknowledgements}

One of the authors (AT) would like to thank UGC, Bhopal, for awarding a teacher research fellowship. The authors are also grateful to the Principal, M.S.J. College, Bharatpur, for providing experimental facilities.

\section{References}

Araktingi I and Hoard R 1999 Proceedings of IPC Expo. '99 (Long Beach, California: Bannockburn, IL: IPC Org.)

Bahl I and Ely K 1990 Microwave J. 33131

Baker-Jarvis J and Janezic M D 1994 Proc. microwave processing of materials IV (Pittsburgh, USA: Mater. Res. Soc.) 347 p. 215

Baker-Jarvis J, Janezic M D, Grosvenor J H and Geyer R G 1994 Natl. Inst. Stand. Technol. NIST Tech. Note 1355

Baker-Jarvis J, Janezic M D, Riddle B and Holloway C L 2001 Natl. Inst. Stand. Technol. NIST Tech. Note 1520

Bur A J 1985 Polymer 26963

Callaghan T A and Paul D R 1994 J. Polym. Sci. Part B: Polym. Phys. 321847

Chang C S 1993 IEEE Comp. Hybrids Mfg. Technol. 16909

Chang C S and Agrawal A P 1994 IEEE Comp. Hybrids Mfg. Technol. 17564

Dube D C 1984 Bull. Mater. Sci. 61075

Dube D C and Natarajan R 1973 J. Appl. Phys. 444927

Eftekhari A, St. Clair A K, Stoakley D M, Kuppa S and Sing J J 1992 J. Polym. Mater. Sci. Eng. 66279

Fayt R, Hadyiandreou P and Teyssie P 1985 J. Polym. Sci. Polym. Chem. Ed. 23337

Khare P K, Gaur M S and Srivastava A P 1993 Indian J. Pure \& Appl. Phys. 31102

Paulter N G 1998 IEEE Trans. Instrum. Meas. 471469

Riddle B and Baker-Jarvis J 2003 IEEE Trans. Microwave Theory \& Technol. $\mathbf{5 1} 727$

Singh J J, St. Clair T L, Holt W H and Mock W 1985 NASA Tech. Memo 86431

Vankrevelen D W and Hoftyzer P J 1976 Properties of polymers (Amsterdam: Elsevier Scientific Publishing Company) 